\title{
The Optimization of Cutting Parameters When High Speed Cutting Thin- walled Workpieces of Hardened Steel Using Micro-end Mill
}

\author{
B.L. ZHANG \& Y.W.XIONG \\ Department of Constructs Environment and Energy engineer, Guilin university of Aerospace Technology, \\ Guilin, China
}

C.LI, H.L.CHEN \& J.C.QIN

Department of Mechanical Engineering, Guilin university of Aerospace Technology, Guilin, China

\begin{abstract}
Based on the orthogonal experiments, using micro-diameter tool milling thin-walled parts of hardened steel in high-speed to research the effects of different cutting parameters on the radial cutting force, vibration, and surface roughness which optimize the cutting parameters. Firstly it make the researching goals into a stability characteristic of product quality named SN ratio, then using principal component analysis make the multi-objective quality characteristics into a single objective quality characteristics combined with analysis of variance to optimize the cutting parameters which not only analyze the significant impacts of cutting parameters on comprehensive quality but also obtained more reasonable cutting parameters and it can be a certain guiding significance for milling thin-walled parts of hardened steel with high speed.
\end{abstract}

KEYWORD: hardened steel; thin-walled work piece; Optimization

\section{INTRODUCTION}

Thin-walled structures abound in the mold, the processing is directly related to the whole mold process efficiency and quality. Domestic and foreign scholars have mainly studied the process of aviation aluminum alloys and titanium of large thin-walled, they study the deformation of thin-walled aluminum alloy due to the low stiffness when process, which solves the problem of the deterioration of work pieces caused by the complexity when processing through theoretical modeling, test analysis and software analysis [1-5]. However, the study of hardened steel thin-walled is not enough in the process of mold, presently. The choose of actual processing parameters strategies are mainly based on the experience of workers which greatly affected the processing efficiency and quality of thin-walled mold. The paper study the radial cutting force, vibration, and surface roughness comprehensively via Taguchi method and principal component analysis when milling thin-walled parts, which optimize the cutting parameters rationally.

\section{EXPERIMENTAL CONDITION AND PROJECT}

\subsection{Experimental condition}

The experiment was carried on an YCM-V85A vertical spindle milling center. The cutter is 4-flutes hard alloy ball end mill with TiSiN-coated and the extended length of cutting tool is $25 \mathrm{~mm}$. The cutting forces are gathered by milling piezoelectric dynamometer named YDX-III9702 which made by Dalian University of Technology, the value of the surface roughness is a mean value measured for three times got by surface roughness-checking instrument named Taylor surf 60 and vibration signals(Power spectrum) are measured by YD-1 piezoelectric accelerometer Sensor.

\subsection{Experimental project}

Spindle speed $(\mathrm{N})$, the radial cutting depth(Rd), axial cutting depth (Ad) and feed rate (fz) can be controlled in the process of milling thin walled parts. Under the condition of controlled variable, it optimize the cutting parameters through researching the targets of cutting force, vibration and surface roughness, which can ensure it and to reduce the cutting force, vibration and improve processing efficiency. The experiment is carried by orthogonal test with $\mathrm{L}_{16}\left(4^{5}\right)$, the test parameters as shown in Table 1. 
Table 1. Orthogonal experimental Parameters paper

\begin{tabular}{|l|c|c|c|c|}
\hline Factors & \multicolumn{4}{|c|}{ levels } \\
\hline Spindle speed N(rpm) & 6366 & 5570 & 4774 & 3978 \\
\hline Radial cutting depth Ae (mm) & 0.08 & 0.10 & 0.12 & 0.14 \\
\hline Axial cutting depth Ad (mm) & 2.50 & 3.00 & 3.50 & 4.00 \\
\hline Feed engement fz (mm/z) & 0.025 & 0.03 & 0.035 & 0.04 \\
\hline
\end{tabular}

\section{THE THEOY OF TAGUCHI METHOD AND PRINCIPAL COMPONENT ANALYSIS[6-7]}

Taguchi method, also known as three design methods, is a famous Japanese scholar, Dr. Taguchi Genichi founded an optimal design method in the 1970s. Its basic idea is to introduce signal to noise ratio (SN ratio) to orthogonal experiment as a measurement of the stability characteristics of targets. Product's quality objectives are divided into: definite purpose, smaller-the-better characteristic and larger-the-better. The ultimate goal is to make the quality target controlled within the allowable range and the fluctuation is relatively small.

PCA's (Principal Components Analysis) main idea is to adopt reduced dimension which make multi-dimensionality target reduce into one or few comprehensive targets, but they can al-so reflect the overall quality character-istics as more as possible. The main analysis steps are as follows:

(1)Standardization of the original target data.

Collect $\mathrm{P}$-dimensional random vector $\mathrm{x}=$ $\left(\mathrm{X}_{1}, \mathrm{X}_{2}, \ldots, \mathrm{Xp}\right)^{\mathrm{T}}, \mathrm{n}$ samples $\mathrm{x}_{\mathrm{i}}=\left(\mathrm{X}_{\mathrm{i} 1}, \mathrm{X}_{\mathrm{i} 2}, \ldots, \mathrm{X}_{\mathrm{p}}\right)^{\mathrm{T}}$, $i=1,2, \ldots, n,(n>p)$. So can get matrix $X$ :

$$
X=\left[\begin{array}{ccccc}
X_{11} & X_{12} & X_{13} & \ldots . & X_{1 p} \\
X_{21} & X_{22} & X_{23} & \ldots . & X_{2 P} \\
X_{31} & X_{32} & X_{33} & \ldots . & X_{3 P} \\
\ldots . & \ldots & \ldots . & \ldots & \ldots . \\
X_{n 1} & X_{n 2} & X_{n 3} & \ldots . & X_{n p}
\end{array}\right]
$$

(2)In order to keep each target's dimension same for comparable, it need to standardize the matrix X. standardization formula as below:

$$
Z_{i j}=\frac{x_{i j}-\min _{1 \leq i \leq n} x_{i j}}{\max _{1 \leq i \leq n} x_{i j}-\min _{1 \leq i \leq n} x_{i j}}
$$

And $i=1,2,3 \ldots n, j=1,2, \ldots$.

(3)Calculate the standardized matrix Z's correlation matrix $\mathrm{R}=\left({ }^{r_{i j}}\right)$ and get its characteristic equation.

$$
|R-\lambda I|=0
$$

Its' solutions are latent root $\lambda_{i}$ which make sort ascending: $\lambda_{1} \geq \lambda_{2} \geq \cdots \geq \lambda_{p}>0$.

The size of characteristic values reflects the importance of each principal components in the composite indicator described. The correlation coefficient matrix can get from formula(4):

$$
r_{i j}=z_{i j} /\left(\sqrt{z_{i j}} \sqrt{z_{i j}}\right)=\sum_{k=1}^{n} z_{k i} z_{k j}, i, j=1,2, \cdots, p
$$

(4)Determine contribution rate of I 's principal components from formula(5):

$$
\frac{\lambda_{i}}{\sum_{j=1}^{p} \lambda_{j}} \times 100 \%
$$

(5)Determine contribution rate of the first m's $\quad B_{1}, B_{2} \cdots, B_{m} \quad, \quad B_{j}=\left(b_{1 j}, b_{2 j}, \cdots b_{m j}\right)^{T} \quad$ from formula(6):

$$
\frac{\sum_{i=1}^{m} \lambda_{i}}{\sum_{j=1}^{p} \lambda_{j}} \times 100 \%
$$

If the accumulated variance contribution rate can reach $85 \%$, for each $\lambda_{j}, j=1,2, \cdots, m$, solve equations $R b=\lambda_{j} b$ obtaining the corresponding orthonormal eigenvectors:

$$
B_{1}, B_{2} \cdots, B_{m}, B_{j}=\left(b_{1 j}, b_{2 j}, \cdots b_{m j}\right)^{T} \text { and get } \mathrm{m}
$$
principal components thereout from formula(7).

$$
C_{j}=Z \times B_{j}(j=1,2, \cdots, m)
$$

(6)The comprehensive evaluation of $m$ principal components. Using formula (8) to get the sum of $\mathrm{m}$ principal components' weigh, denoted by the final evaluation value, weights are each main component's variance contribution rate.

$$
C=\frac{1}{\sum_{i=1}^{m} \lambda_{i}}\left(\lambda_{1} Z_{1}+\lambda_{2} Z_{2}+\lambda_{3} Z_{3}+\cdots+\lambda_{m} Z_{m}\right)
$$

\section{ANALYSIS OF TEST RESULTS}

In the processing of milling hardened steel thinwalled, the main impact factors of cutting force, vibration and the parts' surface roughness is the spindle speed, the radial cutting depth, axial cutting depth and feed per tooth. According to orthogonal test table and their experimental results, it measured the cutting parameters comprehensively and optimized.

Radial cutting force $\mathrm{Fx}$, vibration $\mathrm{Vx}$, surface roughness $\mathrm{Ra}$ Measured by orthogonal experiment are shown in Table 2. 
Table 2 Orthogonal experimental Results of Fx, Vx and Ra

\begin{tabular}{|c|c|c|c|c|c|c|c|}
\hline NO. & $\begin{array}{c}\mathrm{N} \\
(\mathrm{rpm})\end{array}$ & $\begin{array}{c}\mathrm{Rd} \\
(\mathrm{mm})\end{array}$ & $\begin{array}{c}\mathrm{Ad} \\
(\mathrm{mm})\end{array}$ & $\begin{array}{c}\mathrm{Fz} \\
(\mathrm{mm} / \mathrm{z})\end{array}$ & $\begin{array}{c}\mathrm{Fx} \\
(\mathrm{N})\end{array}$ & $\begin{array}{c}\mathrm{Vx} \\
(\mu \mathrm{V})\end{array}$ & $\begin{array}{c}\mathrm{Ra} \\
(\mu \mathrm{m})\end{array}$ \\
\hline 1 & 6366 & 0.08 & 2.5 & 0.025 & 30 & 9.83 & 5.9 \\
\hline 2 & 6366 & 0.10 & 3 & 0.03 & 39 & 10.58 & 5.6 \\
\hline 3 & 6366 & 0.12 & 3.5 & 0.035 & 53 & 22.34 & 6.1 \\
\hline 4 & 6366 & 0.14 & 4 & 0.04 & 60 & 25.68 & 8.5 \\
\hline 5 & 5570 & 0.08 & 3 & 0.035 & 45 & 13.57 & 1.2 \\
\hline 6 & 5570 & 0.10 & 2.5 & 0.04 & 50 & 18.76 & 1.3 \\
\hline 7 & 5570 & 0.12 & 4 & 0.025 & 50 & 20.1 & 7.6 \\
\hline 8 & 5570 & 0.14 & 3.5 & 0.03 & 58 & 23.84 & 6.3 \\
\hline 9 & 4774 & 0.08 & 3.5 & 0.04 & 42 & 11.24 & 1.5 \\
\hline 10 & 4774 & 0.10 & 4 & 0.035 & 40 & 9.051 & 6.4 \\
\hline 11 & 4774 & 0.12 & 2.5 & 0.03 & 42 & 10.22 & 5.3 \\
\hline 12 & 4774 & 0.14 & 3 & 0.025 & 45 & 15.67 & 5.3 \\
\hline 13 & 3978 & 0.08 & 4 & 0.03 & 40 & 11.02 & 4.8 \\
\hline 14 & 3978 & 0.10 & 3.5 & 0.025 & 45 & 16.4 & 7.8 \\
\hline 15 & 3978 & 0.12 & 3 & 0.04 & 55 & 10.81 & 7.2 \\
\hline 16 & 3978 & 0.14 & 2.5 & 0.035 & 55 & 22.9 & 8.7 \\
\hline
\end{tabular}

According to Taguchi's classification based on goals of product quality, the cutting force is hoped as small as possible in the process of milling thinwalled parts which can reduce the deformation of the coupling tool and parts, increasing tools life, etc, so it can be seen smaller-the-better characteristic; The vibration is also as small as possible because it not only can improve the stability of the cutting process but can improve part surface quality, which also belongs to smaller-the-better characteristic. The final surface roughness of thin-walled parts are also smaller-the-better characteristic.

According to the SN ratio formula of smaller-thebetter characteristic (9).

$$
S / N=-10 \lg \frac{\sum_{i=1}^{n}\left(y_{i}\right)^{2}}{n}
$$

We can calculate the $\mathrm{SN}$ ratio of radial cutting force, vibration, and surface roughness when highspeed milling hardened steel thin-walled parts and the results are shown as table 3 .
Table 3 The SN ratio of Fx, Vx and Ra

\begin{tabular}{|c|c|c|c|c|c|c|}
\hline NO. & $\begin{array}{c}F x \\
(\mathrm{~N})\end{array}$ & $\begin{array}{c}\mathrm{Vx} \\
(\mu \mathrm{V})\end{array}$ & $\begin{array}{c}\mathrm{Ra} \\
(\mu \mathrm{m})\end{array}$ & $\begin{array}{c}\mathrm{Fx} \\
\text { SN ratio }\end{array}$ & $\begin{array}{c}\mathrm{Vx} \\
\text { SN ratio }\end{array}$ & $\begin{array}{c}\mathrm{Ra} \\
\text { SN ratio }\end{array}$ \\
\hline 1 & 30 & 9.8 & 5.9 & -29.5 & -19.9 & -15.4 \\
\hline 2 & 39 & 10.6 & 5.6 & -31.8 & -20.5 & -15.0 \\
\hline 3 & 53 & 22.3 & 6.1 & -34.5 & -27.0 & -15.7 \\
\hline 4 & 60 & 25.7 & 8.5 & -35.6 & -28.2 & -18.6 \\
\hline 5 & 45 & 13.6 & 1.2 & -33.1 & -22.7 & -1.6 \\
\hline 6 & 50 & 18.8 & 1.3 & -34.0 & -25.5 & -2.3 \\
\hline 7 & 50 & 20.1 & 7.6 & -34.0 & -26.1 & -17.6 \\
\hline 8 & 58 & 23.8 & 6.3 & -35.3 & -27.5 & -16.0 \\
\hline 9 & 42 & 11.2 & 1.5 & -32.5 & -21.0 & -3.5 \\
\hline 10 & 40 & 9.1 & 6.4 & -32.0 & -19.1 & -16.1 \\
\hline 11 & 42 & 10.2 & 5.3 & -32.5 & -20.2 & -14.5 \\
\hline 12 & 45 & 15.7 & 5.3 & -33.1 & -23.9 & -14.5 \\
\hline 13 & 40 & 11.0 & 4.8 & -32.0 & -20.8 & -13.6 \\
\hline 14 & 45 & 16.4 & 7.8 & -33.1 & -24.3 & -17.8 \\
\hline 15 & 55 & 10.8 & 7.2 & -34.8 & -20.7 & -17.1 \\
\hline 16 & 55 & 22.9 & 8.7 & -34.8 & -27.2 & -18.8 \\
\hline
\end{tabular}

Based on PCA can calculate correlation coefficient matrix R's eigenvalues getting contribution rate of each main component which as shown in table 4.

Table 4 Each principal component's eigenvalue and variance contribution rate

\begin{tabular}{|c|c|c|c|}
\hline NO. & eigenvalue & $\begin{array}{c}\text { variance } \\
\text { contribution rate(\%) }\end{array}$ & $\begin{array}{c}\text { cumulative variance } \\
\text { contribution rate(\%) }\end{array}$ \\
\hline 1 & 0.181869 & 60.4092 & 60.41 \\
\hline 2 & 0.101254 & 33.6322 & 94.04 \\
\hline 3 & 0.017939 & 5.9586 & 100 \\
\hline
\end{tabular}

As can be seen from Table 4, the cumulative variance contribution rate corresponding to the first two eigenvalues reaches $94.04 \%$, so the first two principal components can reflect the original target's most information which can use to evaluate comprehensive characteristic when high speed milling hardened steel thin walled parts. The proportions of the principal components are shown in figure 1 via visual map. Eigenvectors of the first two principal components are B1and B2.

$$
\begin{aligned}
& B_{1}=\left[\begin{array}{lll}
0.5322 & 0.7666 & 0.3592
\end{array}\right]^{\mathrm{T}} \\
& B_{2}=\left[\begin{array}{lll}
-0.2048 & -0.2951 & 0.9333
\end{array}\right]^{\mathrm{T}}
\end{aligned}
$$
C2.

The first two principal components are $\mathrm{C} 1$ and

$$
\begin{aligned}
& C_{1}=0.5322 Z_{1}+0.7666 Z_{2}+0.3592 Z_{3} \\
& C_{2}=-0.2048 Z_{1}-0.29510 Z_{2}+0.9333 Z_{3}
\end{aligned}
$$

It can be seen from the first two principal components (Fig. 1): the first principal component is greater affected by index value of vibration, while the target of surface roughness' effects on the 
second principal component is more obvious. Thus calculate the values of 16 samples under the first two principal components which shown in Table 5.

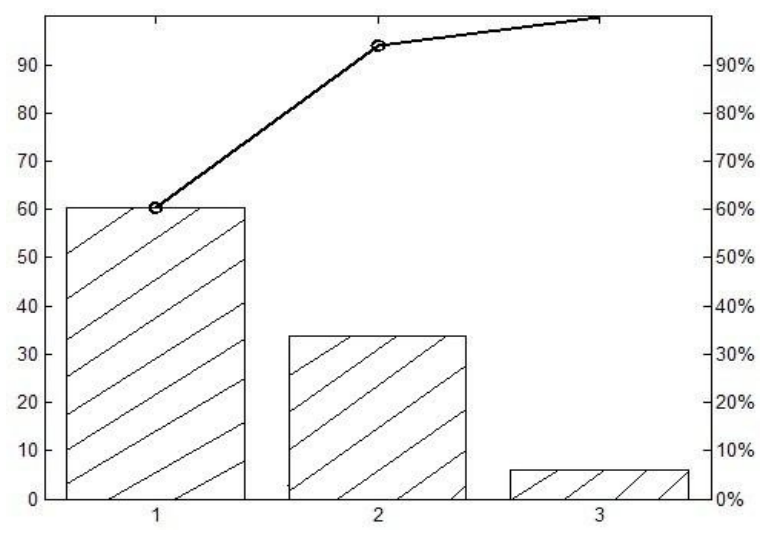

Fig.1 Each principal intuitionistic figure

Table 5 Each samples'score

\begin{tabular}{|c|c|c|c|c|c|c|}
\hline Z1 & Z2 & Z3 & $\begin{array}{c}\text { C1's } \\
\text { score }\end{array}$ & $\begin{array}{c}\text { C2's } \\
\text { score }\end{array}$ & $\begin{array}{c}\text { composite } \\
\text { score C }\end{array}$ & $\begin{array}{c}\text { To } \\
\text { sort }\end{array}$ \\
\hline 1.00 & 0.92 & 0.20 & 1.31 & -0.29 & 0.69 & 3 \\
\hline 0.62 & 0.85 & 0.22 & 1.06 & -0.17 & 0.58 & 7 \\
\hline 0.18 & 0.13 & 0.18 & 0.26 & 0.09 & 0.19 & 12 \\
\hline 0.00 & 0.00 & 0.01 & 0.00 & 0.01 & 0.01 & 16 \\
\hline 0.42 & 0.61 & 1.00 & 1.05 & 0.67 & 0.86 & 2 \\
\hline 0.26 & 0.30 & 0.96 & 0.72 & 0.75 & 0.69 & 4 \\
\hline 0.26 & 0.23 & 0.07 & 0.34 & -0.06 & 0.19 & 13 \\
\hline 0.05 & 0.07 & 0.16 & 0.14 & 0.12 & 0.12 & 14 \\
\hline 0.51 & 0.79 & 0.89 & 1.20 & 0.49 & 0.89 & 1 \\
\hline 0.59 & 1.00 & 0.16 & 1.13 & -0.27 & 0.59 & 6 \\
\hline 0.51 & 0.88 & 0.25 & 1.04 & -0.13 & 0.58 & 8 \\
\hline 0.42 & 0.47 & 0.25 & 0.67 & 0.01 & 0.41 & 9 \\
\hline 0.59 & 0.81 & 0.30 & 1.04 & -0.08 & 0.60 & 5 \\
\hline 0.42 & 0.43 & 0.06 & 0.57 & -0.16 & 0.29 & 11 \\
\hline 0.13 & 0.83 & 0.10 & 0.74 & -0.18 & 0.38 & 10 \\
\hline 0.13 & 0.11 & 0.00 & 0.15 & -0.06 & 0.07 & 15 \\
\hline
\end{tabular}

In order to simplify the analysis process, mading the composite score $\mathrm{C}$ of the first two principal components as one the composite score as considering index, which would made multiple indexes into a new comprehensive survey indicators, improving reasonableness of the optimization results. Carrying out analysis of variance for the composite index $\mathrm{C}$ optimize the cutting parameters.

As can be seen from Table 7, the radial cutting depth has significant impact on the composite index, followed by the spindle speed $\mathrm{N}$, the axial cutting depth Ad and feed speed has weaker impact. We can see from table 6 that the optimal cutting combination is $N_{3} R d_{1} A d_{2} f z_{4}$, that $\mathrm{N}=4774 \mathrm{RPM}, \mathrm{Rd}=0.08 \mathrm{~mm}$, $\mathrm{Ad}=3 \mathrm{~mm}, \mathrm{fz}=0.04 \mathrm{~mm} / \mathrm{z}$. Seen from the listed orthogonal table, the ninth test parameters is closest to value of optimal combination of milling parameters and its has highest score known from the each index's. As can be seen from Table 6, as the feed speed fz has minimal impact on the composite indicator C. Allowing the part surface quality, it can increase the feed speed to improve processing efficiency when the cutting depth controlled and the composite indicator $\mathrm{C}$ is bigger and there has smaller difference when the axial cutting depth of $2.5 \mathrm{~mm}$ and $3 \mathrm{~mm}$, so we can choose axial cutting depth of $2.5-3 \mathrm{~mm}$ for better surface roughness, at the same time, in the condition of surface roughness' permission we can increase the axial cutting depth for higher efficiency.

Table 6 Integrative index table

\begin{tabular}{|c|c|c|c|c|c|c|}
\hline NO. & $\begin{array}{c}\mathrm{N} \\
(\mathrm{rpm})\end{array}$ & $\begin{array}{c}\mathrm{Rd} \\
(\mathrm{mm})\end{array}$ & $\begin{array}{c}\mathrm{Ad} \\
(\mathrm{mm})\end{array}$ & $\begin{array}{c}\mathrm{fz} \\
(\mathrm{mm} / \mathrm{z})\end{array}$ & $\mathrm{C}$ & $\mathrm{C} 2$ \\
\hline 1 & 6366 & 0.08 & 2.50 & 0.03 & 0.69 & 0.79 \\
\hline 2 & 6366 & 0.10 & 3.00 & 0.03 & 0.58 & 0.35 \\
\hline 3 & 6366 & 0.12 & 3.50 & 0.04 & 0.19 & 0.34 \\
\hline 4 & 6366 & 0.14 & 4.00 & 0.04 & 0.01 & 0.17 \\
\hline 5 & 5570 & 0.08 & 3.00 & 0.04 & 0.86 & 0.74 \\
\hline 6 & 5570 & 0.10 & 2.50 & 0.04 & 0.69 & 0.47 \\
\hline 7 & 5570 & 0.12 & 4.00 & 0.03 & 0.19 & 0.04 \\
\hline 8 & 5570 & 0.14 & 3.50 & 0.03 & 0.12 & 0.02 \\
\hline 9 & 4774 & 0.08 & 3.50 & 0.04 & 0.89 & 0.48 \\
\hline 10 & 4774 & 0.10 & 4.00 & 0.04 & 0.59 & 0.34 \\
\hline 11 & 4774 & 0.12 & 2.50 & 0.03 & 0.58 & 0.04 \\
\hline 12 & 4774 & 0.14 & 3.00 & 0.03 & 0.41 & 0.00 \\
\hline 13 & 3978 & 0.08 & 4.00 & 0.03 & 0.60 & 0.36 \\
\hline 14 & 3978 & 0.10 & 3.50 & 0.03 & 0.29 & 0.08 \\
\hline 15 & 3978 & 0.12 & 3.00 & 0.04 & 0.38 & 0.15 \\
\hline 16 & 3978 & 0.14 & 2.50 & 0.04 & 0.07 & 0.01 \\
\hline $\mathrm{T} 1$ & 1.47 & 3.04 & 2.03 & 1.58 & & \\
\hline $\mathrm{T} 2$ & 1.86 & 2.15 & 2.24 & 1.90 & & \\
\hline T3 & 2.48 & 1.35 & 1.49 & 1.71 & & \\
\hline $\mathrm{T} 4$ & 1.35 & 0.61 & 1.39 & 1.97 & & \\
\hline$T_{1}^{2}$ & 2.17 & 9.25 & 4.13 & 2.50 & & \\
\hline$T_{2}^{2}$ & 3.45 & 4.64 & 5.00 & 3.59 & & \\
\hline$T_{3}^{2}$ & 6.14 & 1.81 & 2.23 & 2.93 & & \\
\hline$T_{4}^{2}$ & 1.82 & 0.38 & 1.93 & 3.86 & & \\
\hline average & 3.39 & 4.02 & 3.33 & 3.22 & & \\
\hline$S$ & 0.19 & 0.82 & 0.13 & 0.02 & & \\
\hline
\end{tabular}


Table 7 Integrative index variance ananlyical table

\begin{tabular}{|c|c|c|c|c|}
\hline Source of squre error & ss & df & $\mathrm{ms}$ & $\mathrm{F}$ \\
\hline $\mathrm{N}$ & 0.1933 & 3 & 0.0644 & 51.0990 \\
\hline $\mathrm{Rd}$ & 0.8207 & 3 & 0.2736 & 216.9721 \\
\hline $\mathrm{Ad}$ & 0.1266 & 3 & 0.0422 & 33.4575 \\
\hline $\mathrm{fz}$ & 0.0229 & 3 & 0.0076 & 6.0630 \\
\hline Error & 0.0038 & 3 & 0.0013 & \\
\hline Sum & 1.1673 & 15 & & \\
\hline & & & &
\end{tabular}

\section{CONLUSIONS}

Reasonable cutting parameter is a key to improve surface quality and processing efficiency. Thinwalled parts not only has complex configuration which is hard for machining but as its low rigidity, it is easy for deformation when processing which bring worse surface roughness. Based on high speed milling thin walled work piece, the paper adopt Taguchi method and principal component analysis to optimize the cutting parameters and get following conclusions.

(1) Adopting taguchi method and principal component analysis made the product quality characteristics measured in the form of SN ratio and made multiple affecting factors into single composite index with the method of dimension reduction which improves the stability of product quality getting reliable optimization rusults.

(2) Known from the results of analysis of variance that affecting factors' for products' machining quality that cutting parameters' significance is $\mathrm{Rd}>\mathrm{N}>\mathrm{Ad}>\mathrm{fz}$, so it can increase feeding speed to improve process efficiency properly in actual production.

(3) It can obtain better machining quality when the axial cutting depth is between $2.5-3 \mathrm{~mm}$, the optimal cutting parameters is $\mathrm{N}=4774 \mathrm{RPM}$, $\mathrm{Rd}=0.08 \mathrm{~mm}, \mathrm{Ad}=3 \mathrm{~mm}, \mathrm{fz}=0.04 \mathrm{~mm} / \mathrm{z}$.

\section{ACKNOWLEDGEMENT}

The project supported by the National Science Foundation of Guilin university of aerospace technology(YJ1307)

\section{REFERENCES}

[1] Z.Q.Ao, J.J.Wu and Z.Q.Wang: Machine Tool \& Hydrulics. 2007, 35(2): 15-18

[2] Z.G.Wang and P.Zhang: Aviation Precision Manufacturing Technology. 2000, 36(6):7-11

[3] D.Umbrello .Finite Journal of materials processing technology 2008 (196):79-87

[4] E.Budak: Vancouver Canada: The university of British Columbia, 1994

[5] J.K.Rai, P.Xirouchakis, International Journal of Machine Tools and Manufacture. 2008 (48):629-643

[6] X.F.Zhong, Z.J.Han: Journal of Nanjing University of Science and Technology. 2003, 27(3):301-304

[7] A.G.hani,I, H.Choudhury and H.Hassan. Journal of Materials Processing Technology. 2004(145):84-92 